\title{
LA LANZA BAJOMEDIEVAL CASTELLANA: UNA PROPUESTA SOBRE SU ORIGEN
}

\author{
Manuel Ángel Martín Vera ${ }^{1}$ \\ Universidad de Sevilla
}

Recibido: 24 de junio de 2020

Aceptado: 24 de diciembre de 2020

\begin{abstract}
Resumen
Este trabajo pretende incidir en el tema de la lanza Castellana, realizando una propuesta sobre su origen, y poniendo de manifiesto nuestra postura ante un problema latente: la cuestión ha sido abordada por gran parte de la historiografía desde diversos enfoques que, lejos de despejar dudas, han generado cierta confusión. Uno de ellos es el marco temporal, pues, aunque los datos disponibles permiten establecer un ámbito cronológico concreto para la aparición de la lanza en Castilla, algunos autores han planteado ciertas hipótesis, como resultado de rastrear antecedentes semánticos en todo tipo de textos, principalmente literarios; o a través de pistas indiciarias de carácter organizativo-militar. Otra línea de investigación, también de carácter militar, ha orientado sus pesquisas a buscar equivalencias en el entorno europeo bajomedieval.
\end{abstract}

\section{Palabras clave}

Lanza Castellana, Tácticas terrestres, Baja Edad Media, Unidad militar, Organización militar.

\begin{abstract}
This paper addresses the Castilian lanza, making a proposal on its origin, and reveals our stance on an underlying issue regarding this topic: it has been discussed by many Historians from different perspectives that, far from removing all doubt, have generated some confusion. One of these is the time frame. While the available data allow to determine a specific point in time for the emergence of the lanza in Castile, some authors have formulated different hypotheses as a result of either tracking semantic records in all kinds of texts -mainly literary- or following evidence in a military-organizational context. Another research line, also military-related, has been focused on finding equivalents in other late medieval European territories.
\end{abstract}

\section{Keywords}

Castilian Lanza, Ground Tactics, Late Middle Ages, Military Unit, Military Organization.

\section{Résumé}

Cet article aborde la lanza castillane, faire une proposition sur son origine, et révèle notre position sur un problème sous-jacent concernant ce sujet: il a été discuté par de nombreux historiens sous des angles différents qui, loin de dissiper les doutes, ont généré une certaine confusion. L'un d'entre

Doctor en Historia Medieval por la Universidad de Sevilla y miembro del grupo de investigación HUM214 del PAIDI de la Junta de Andalucía: El reino de Sevilla en la Baja Edad Media. https://investigacion. us.es/sisius/sis_showpub.php?idpers=26908. Correo electrónico: manu28sev@hotmail.com. OrCID: https:// orcid.org/0000-0003-4164-960X. 
eux est le cadre temporel. Bien que les données disponibles permettent de déterminer un moment précis pour l'émergence de la lanza en Castille, certains auteurs ont formulé différentes hypothèses en suivant des antécédents sémantiques dans textes de toute sorte -principalement littéraires- ou des pistes indiciaires dans le contexte de l'organisation militaire. Une autre ligne de recherche, également à caractère militaire, s'est concentrée sur la recherche d'équivalents dans d'autres territoires européens à la fin du Moyen Âge.

\section{Mots-clés}

Lance castillane, Tactiques terrestres, Bas Moyen Âge, Unité militaire, Organisation militaire.

\section{Introducción}

Para desarrollar el trabajo ${ }^{2}$, hemos aplicado el método historiográfico, combinado con el modelo de estudios comparados — similar a los empleados por los profesores Ladero Quesada y García Fitz-. La hipótesis de partida pretende establecer que el origen conceptual de la lanza $a^{3}$ castellana no es de carácter semántico u organizativo, sino fruto de la normativa regia, que reguló la montura y equipación militar, y cuyos antecedentes terminológicos pueden rastrearse en otros conflictos donde intervinieron las Compañías extranjeras, y en partes del equipo que se incorporó progresivamente, conforme sugiere la Crónica Abreviada de López de Ayala.

La lanza castellana es un tema poco estudiado. Hay autores que se apoyan en observaciones, comentarios, hipótesis u opiniones de otros, para formular propuestas que estimamos deben ser analizadas con detenimiento y a la luz de los documentos disponibles, pues afectan a asuntos tales como: el origen del concepto, su posible inclusión en la estructura militar de la época, su consideración como "Unidad táctica", el mando de dicha fuerza, los efectivos que la integran, sus capacidades bélicas, etc.

En definitiva, buscamos enriquecer el debate, poner de manifiesto lo que sabemos y reflexionar sobre la evidencia, para alcanzar entre todos un consenso a nivel histórico.

\section{La cuestión cronológica y las fuentes}

Una de las cuestiones fundamentales estriba en determinar el marco cronológico donde surge la noción de lanza, entendida como combatiente dotado de caballo, armas y

\footnotetext{
2 Presentamos un primer esbozo del tema en la comunicación: "La organización de las Órdenes Militares en la Castilla bajomedieval: claves de su actuación", del Seminario Internacional "Murum et clipeum Christianitatis. Las Órdenes militares y la guerra". Sevilla, 16-17/11/2018. Organizado por la Asociación Ibérica de Historia Militar. Siglos IV-XVI [AIHM], el Dpto. de Historia Medieval y CC. y TT. HH. de la Facultad de Geografía e Historia de la Universidad de Sevilla, y la Cátedra General Castaños. Y en: Los orígenes del Ejército Moderno en el reino de Castilla, siglos XIV-XV, pp. 229-243 [Tesis Doctoral Inédita], formulamos las principales cuestiones que ahora desarrollamos en extenso.

3 Para diferenciarla del arma ofensiva del mismo nombre, optamos por escribir la palabra en cursiva.
} 
equipos, conforme a los Ordenamientos reales; y al que se le exige mantener una disponibilidad - sea por sus capacidades económicas o cuantías, o por los acostamientos que perciben como vasallos-, y llegado el caso, prestar un servicio armado.

\subsection{Rastreando el origen}

Con objeto de indagar sobre el origen del concepto lanza - aunque los datos actuales constatan que surge a partir del segundo tercio del siglo XIV-, algunos autores han llevado a cabo una minuciosa búsqueda en fuentes, sobre todo literarias y documentales, que han dado como fruto dos tipos de propuestas. Una de índole semántica, a través del análisis de ciertas expresiones literarias; y la otra de carácter dispositivo, que afecta a una orden militar en concreto.

La primera postura la representa Palacios Ontalva ${ }^{4}$, que propone: "la aparición de dicha realidad [concepto lanza] (seguramente en las primeras décadas del siglo XII) (...) así como en la evolución semántica del mismo seguida hasta finales del siglo XV". Desarrollando más adelante la idea, expone: "El concepto fue fraguando y adquiriendo un campo semántico que, en sentido figurado, se refería a un guerrero u hombre de armas destacado por sus dotes militares" palabra que Gago Jover reproduce en su Vocabulario, a través de un pasaje del Libro de Alexandre: "lança fardida" —obra del siglo XIV ${ }^{6}$. Y para concluir, en sus valoraciones finales sostiene: "Aunque el término 'lanza' fuera empleado desde el siglo XII como sinónimo y personificación del caballero o combatiente montado a caballo y armado con tal artefacto (...), la aparición del término (...) hemos de situarlo en la segunda mitad del siglo XIV". O sea, habla de un uso, que no aparece [¿se fija?] hasta siglos más tarde. Sin embargo, admite no poder "definir" el término en muchos aspectos, por considerar insuficientes los tanteos historiográficos y testimonios textuales o documentos?

Como podemos comprobar, el autor sitúa en el siglo XII el posible arranque en su plano lingüístico, y su evolución en el campo semántico, hasta la aparición del término tras el reinado de Alfonso XI. Nos interesa plantear una cuestión: ¿hasta qué punto el empleo de una figura literaria, la sinécdoque - aplicar a un todo el nombre de una parte, o viceversa, o sea, la lanza como arma, por el guerrero que la porta-, puede ser considerado el origen de la lanza castellana? Existen más casos de sinécdoque relacionados con la espada, y ello no da lugar al surgimiento de esa voz, en términos ni similares ni aproximados a los que concurren con el concepto lanza.

\footnotetext{
Palacios Ontalva, "Una aproximación...”, pp. 297-320.

Ibidem, pp. 297 [1 ${ }^{\mathrm{a}}$ cita], 306-307 [2 $2^{\mathrm{a}}$ cita, nota 27].

"En sentido figurado, guerrero, hombre de armas". GAGO-Jover, Vocabulario militar, p. 229. Fardido: atrevido, osado. RAE, Diccionario..., 1791, p. 422,3, http://buscon.rae.es/ntlle/SrvltGUISalirNtlle Aunque Jover aclara: la voz lanza se aplicaba tanto al que luchaba con ella a pie, como al de a caballo. GAGO-JOVER, "El léxico militar en el Poema de Alfonso XI", pp. 457-509.

7 Palacios Ontalva, “Una aproximación..., p. 317.
} 
Bajo nuestro punto de vista, estamos convencidos de que nada tiene que ver el uso histórico de una figura literaria con el tema que nos ocupa, pues la noción lanza para Castilla, arranca de otra que ya tenía nombre propio: el "hombre de armas"

La segunda propuesta, ésta de naturaleza normativa, viene de la mano del profesor Ayala Martínez. Se basa en un texto manuscrito de 1274, que afectaba a los freires comendadores santiaguistas, estableciendo que: "traygan consigo un freyle morador e dos ommes de cavallo e çinco ommes de pie porque en el tiempo de la guerra cada uno ha de yr lo mejor acompañado que pudiere (BN., Ms. 8.582, fol. 47v)"'. Con toda probabilidad, pues queda patente en varios de sus trabajos, el manuscrito le sirve de base para proponer: "En torno a 1300 (...). Estamos muy probablemente ante el origen, entre las órdenes militares, del concepto de lanza"10.

En su conjunto, esta propuesta reviste dos vertientes. La que valoramos en este apartado atañe al concepto lanza. La otra concierne al número de componentes, materia que abordaremos en el punto 3.2.

Como matiz capital y más significativo del precepto, resaltamos la conveniencia de contextualizar su finalidad: ir en tiempo de guerra lo mejor acompañado, de manera que esa fuerza aportada por la encomienda a la mesnada señorial o a la hueste real, tenga una entidad o dimensión determinada, y al mismo tiempo, dicho grupo sea lo suficientemente relevante y plural - jinetes y peones-, como para proporcionar seguridad mutua al conjunto, en su trayecto hasta la zona de reunión, en un periodo de guerra -ya de por sí inestable-, al que se sumaría el riesgo de ataques por parte de los habituales merodeadores y salteadores de caminos. En consecuencia, no encontramos en esta cita documental ningún elemento que nos sirva de referencia o nos aproxime al concepto de lanza castellana.

\subsection{Las fuentes}

La pista nos conduce directamente a los reinados de Pedro I y Enrique II. La data más temprana es de 1366: "a daqui comenzaron tantas lanzas""11. Aparece en la Crónica de López de Ayala, como nota de la Abreviada para el reinado de Pedro I, en un fragmento relacionado con las compañías extranjeras implicadas en la guerra civil que sostuvo contra su hermanastro Enrique. La lanza se vuelve a mencionar para el mismo año, ahora en el cuerpo de la Crónica, de nuevo vinculada a "Compañas es-

\footnotetext{
8 Las Siete Partidas del rey Don Alfonso el Sabio, vol. 2, pp. 245 [Part. 2, tít. 23, ley 19, abrev.: P.2.23.19: "home de caballo"], 262 [P.2.24.6: "homes de armas"], 576 [P.3.18.51: "caballero de armas"].

9 Ayala Martínez, "Participación y significado de las Órdenes Militares en la conquista de Carmona", p. 162 [nota 50]; "Bienes y rentas de las Órdenes Militares castellano-leonesas (ss. XII-XIV). Balance y perspectivas de análisis", pp. 8-10 [nota 6]; Las órdenes militares hispánicas en la Edad Media (siglos $X I I-X V)$, pp. 542 [nota 3], 554.

10 Ibidem, p. 555.

11 López de Ayala, "Crónica del rey Don Pedro", vol. 1, p. 537 [nota 2]. Sobre la Abreviada. Ibidem, p. 397.
} 
trangeras" - detalle que reitera en otras citas, para los años 1367 y $1369-{ }^{12}$. En el relato del cronista, nos interesa resaltar dos puntos. El primero, la equiparación que hace para 1367 entre hombres de armas de Castilla y lanzas. El segundo, ya en 1369, ampliando el concepto, e integrando a unos y otros: "podían ser todos Castellanos é Ginetes tres mil lanzas"13.

Del periodo de Enrique II, y aunque en los Ordenamientos de Cortes de su mandato no se trate la lanza, destacamos por su interés una misiva a Murcia fechada en 1372 y reproducida en su Crónica, que alude a ella como parte integral de la hueste castellana, o sea, como concepto asumido ${ }^{14}$. Y apenas iniciar su Crónica Ayala, la Abreviada la cita para $1370,1373,1374$, y en el cuerpo para 1376 . De todas las menciones, sobresale la de 1374, donde separa lanzas y jinetes: "fizo facer á los suyos alarde, é falló cinco mil lanzas, é mil docientos ginetes ['lanzas Castellanos é Ginetes', según la Abreviada]"15. Es evidente que, para los contemporáneos de la época, y conforme marca la legislación, ambos tipos de lanza son claramente diferentes.

\section{Organización, mando y composición de la lanza: el tratamiento historiográfico}

A nivel interpretativo, en la introducción de nuestro trabajo alertamos de la proliferación de obras apoyadas en presupuestos ajenos a los testimonios documentales conocidos, y que lejos de suscitar controversia entre los investigadores, han sido aceptados sin mayor discusión.

A los problemas derivados de la delimitación del marco cronológico, se suman los de considerar la lanza como "Unidad táctica", y al hombre de armas como su jefe; incluso se llegan a emplear factores multiplicadores, incrementando el número de sus efectivos, con el propósito de sentar paralelismos con otras fuerzas europeas. Analicemos todo ello de un modo pormenorizado.

\subsection{Paralelismos europeos}

Para que la lanza forme una agrupación, asignándole la categoría de Unidad táctica o fuerza de combate, aunque sea temporal, como cualquier organización humana, deberá sujetarse a algún tipo de regulación, de modo que sus miembros sepan coordinar y complementar su acción; y lo más crucial, quien los lidere, deberá poder hacerlo sobre el conjunto y en todo momento - sobre todo, desde el inicio hasta el final de la acción-. Lo que implica dirigirlos en su forma de desplazarse mientras luchan - a pie o a caballo-, y de combatir - que sabemos se basa en el arma principal que cada uno

\footnotetext{
12 Ibidem, vol. 1, pp. 546 [1366], 550 [1367, Navarra], 553 [Batalla de Nájera], 565, 576, 585 [1369].

13 Ibidem, vol. 1, pp. 578 [1367], 589 [1369]. Aunque su crónica es posterior, las sitúa en fechas concretas.

14 Pascual Martínez, Documentos de Enrique I, p. 150 [doc. de 27/09/1372]; López DE Ayala, "Crónica del rey Don Enrique Segundo", vol. 2, p. 13 [nota 3].

15 Ibidem, vol. 2, pp. 1, 6 [1370, notas 3 y 1], 22 [1373, nota 1], 23 [1374, texto y nota 1], 30-31 [1376].
} 
porta: lanza, ballesta, etc., y condiciona el modo de empleo táctico de dicha Unidad-; porque lo esencial es que todos luchen unidos y bajo mando único, y esto no ocurre con la lanza castellana, que solo dispone de un hombre de armas, asistido por un paje como máximo ${ }^{16}$; y esa unicidad, por ser tan exigua, no puede constituir una Unidad militar ${ }^{17}$. Lo más revelador, es que tampoco concurre la condición de Unidad táctica en otras lanzas europeas, a pesar de su mayor número de integrantes.

La confusión surge al contabilizar a todos, sin discriminar a los que combaten a caballo junto con el hombre de armas, de aquellos que lo hacen a pie - y no pueden seguir el ritmo de las monturas-, y de los sirvientes, criados y pajes, que prestan apoyo logístico o asistencia puntual, sin intervenir activamente en la acción.

Examinemos la situación, siguiendo la evolución de la lanza francesa a través del trabajo de Philippe Contamine: "A mediados del siglo XIV, muchas armaduras de hierro correspondían a dos hombres (de los que solo uno era combatiente) y a dos caballos". $\mathrm{O}$ sea, en este periodo solo había un hombre de armas y un sirviente. "En el siglo XV (...) toda lanza debía contar necesariamente con tres hombres, (...) el hombre de armas (...), un combatiente auxiliar llamado coutilier, y un paje". Ahora son dos combatientes y un sirviente. En la propuesta de Philippe de Mézières para una nueva Orden de Caballería, figuran además del caballero: un escudero armado, dos sirvientes — principal y secundario - y un criado de a pie -5 personas y 4 caballos - Siguen siendo dos combatientes, ahora con tres sirvientes, incluido el criado - a pie-. En sus notas al capítulo IV, Contamine dice: "el noble que servía como hombre de armas debido a su o sus feudos contaba solo, con frecuencia, en la segunda mitad del siglo XV, con dos caballos y un paje"18. En síntesis: la Lanza gala dispondría, por término medio, de uno o dos combatientes - caballero y auxiliar - y un sirviente.

El gran cambio tiene lugar en 1445 con la conocida "grande ordonnance", que crea la "lance fournie o garnie", compuesta por seis hombres y seis caballos en dos grupos. En el primero: un hombre de armas con armadura completa —arnés blanco- y dos auxiliares: un coutillier o coustilleur, y un paje. En el otro, dos arqueros a caballo y un paje que los asistía ${ }^{19}$. De hecho, los consideramos como dos grupos, porque a pesar de marchar unidos bajo mando del caballero, no tiene sentido que los arqueros luchen sobre sus monturas, junto a los hombres de armas y sus acompañantes — se estorbarían, amén de que el tiro sobre caballo requiere un arco corto y entrenamiento especial-. Lo idóneo es agrupar a los arqueros de todas las lanzas y ponerlos en vanguardia o a los flancos, para formar

\footnotetext{
16 La individualidad es manifiesta: "Que cada vno delos dichos nuestros vasallos trayan...". RAH, (ed.), Córtes de los antiguos reinos de León y de Castilla, vol. 2, p. 462 [Juan I. Guadalajara, 1390].

17 Para evitar confusiones, escribimos siempre "Unidad" -fuerza militar- con mayúscula inicial.

18 Contamine, La guerra en la Edad Media, pp. 163, 217.

19 Contamine, Guerre, état el société à la fin du Moyen Âge, p. 278. El coutillier o coustilleur es denominado así por la larga daga de doble filo que porta. También dispone de una jabalina en ristre, que puede usar a modo de pequeña lanza [vid.: nota 5; traducción al texto en: ConTAMINE, La guerra en la Edad Media, p. 164]. Quatrefages, al hablar del coutillier de la lance fournier, lo llama "herrero" -posible errata-. QuATREFages, La revolución militar moderna..., pp. 38, 62 [vid.: nota 90]. Otra ref.: KeEn, Historia de la guerra en la Edad Media, pp. 358, 360.
} 
densas nubes de flechas con las que frenar las cargas de caballería enemiga. En el caso inglés, sus arqueros, equipados con el famoso arco largo — longbow —, actuaron así durante la batalla de Nájera en 1367, usando sus cabalgaduras solo para trasladarse junto a los hombres de $\operatorname{armas}^{20}$. Otro detalle a observar es que cada grupo disponga de su propio paje. Este enfoque que planteamos no es nuevo, Joaquín Sotto y Montes ya lo señaló:

"los servidores de tales lanzas realmente quedaban separados, durante la acción, de los Hombres de Armas a quienes servían (...). Además, los caballeros y sus escuderos combatían a caballo, mientras que los arqueros y pajes actuaban a pie. La falta de acción de conjunto era inevitable"21.

Ahondando en la lance fournie, Contamine apunta algo relevante - reproducimos el párrafo original-: "Ainsi, la lance fournie réunissait dans une même unité, sinon tactique, du mois administrative et sociale, des éléments militaires qui, auparavant, étaient comptés séparément", creando la duda de que se trate realmente de una "Unidad Táctica"; y resaltando que ello permitió establecer el modelo inglés, de relación constante entre "gens d'armes" - hombres de armas- y "gens de trait" — término genérico, equivalente a tropas "troupes", usado para designar arqueros, ballesteros, etc. $-^{22}$. Y Alonso Baquer, al citar la obra del general Weygand, Historie de l'Armée Française, sobre la lance fournie, confirma esta dicotomía entre peones y jinetes:

"La anexión de la [lanza] Borgoñona reforzarán en 1477 a la caballería francesa con estas excelentes compañías, que para la marcha y también para el combate eran reagrupadas por especialidades: caballeros pesados, arqueros y gentes de a pie, que constituían escuadrones y compañías distintas" ${ }^{\prime 23}$.

\subsection{Posturas historiográficas}

Pasemos ahora a analizar la postura adoptada por algunos de los más destacados autores que han tratado la materia. En concreto, nos centraremos en los aspectos que estimamos más controvertidos de la lanza: su composición —número de personas actuantes e implicadas-, funciones, si constituye o no Unidad táctica, etc.

\footnotetext{
20 Así actuaron en la Guerra de los Cien Años. Ibidem, p. 251.

21 Sotto y Montes, “Organización militar de los Reyes Católicos (1474-1517)”, p. 11. No siempre es acertado asociar caballero y escudero; este último tuvo su propia relevancia. Ej.: Pedro I mantuvo una compañía de escuderos "del cuerpo del rey”. LóPEz DE AYALA, "Crónica del rey Don Pedro", vol. 1, pp. 486, 531. En el cerco a Baza de 1489, un ala de la vanguardia era toda de escuderos. Pulgar, "Crónica de los Reyes Católicos", vol. 3, p. 481.

22 Contamine, Guerre, état el société à la fin du Moyen Âge, pp. 278-279 [trad. propia].

23 Alonso Baquer, "Las guerras y su técnica en la época del Renacimiento", p. 350.
} 
Ya en su momento, el profesor Ladero remarcó la singularidad castellana:

"También en sus formas de combatir y en sus armas presenta el castellano características originales. La caballería en Castilla dista mucho de parecerse al modelo francés o borgoñón (...). Los documentos hablan de 'lanças a la gineta' y 'lanças hombres de armas` (...) en ambos casos el caballero combate solo o, todo lo más, acompañado por algún paje"24.

Pero a pesar de la elocuente cita, al abordar la reducción de Lanzas tras la victoria del condestable Álvaro de Luna en 1429, escribe: "Como se trata de 'hombres de armas', hay que multiplicar por tres el número de 300 para estimar el total de personas implicadas directamente en este pequeño ejército real fijo" ${ }^{25}$. Tras consultarle la cuestión, nos despejó la duda:

“al comparar con las 'lanzas' francesa y borgoñona (...), formulé en trabajos más recientes la hipótesis de que el hombre de armas castellano necesitaría, al menos, un rocín auxiliar y una o dos personas que cuidaran de armadura e impedimenta, e incluso que le pudieran auxiliar en algunos momentos o formas de combate. Este es el fundamento de mi hipótesis, pero no conozco documentos fiscales que permitan comprobarla"26.

Otra autoridad en la materia es el profesor Ayala Martínez. En el punto 2.1 nos ocupamos de su propuesta, sustentada en un texto de 1274, y ahora nos corresponde abordar lo tocante al número de componentes de cada lanza. Su proposición a este respecto es la siguiente: "Quizás un equipo compuesto por dos caballeros y dos o tres peones por lanza (...) se ajuste con más exactitud a la realidad peninsular"27. En concreto, y para las órdenes, llega a detallar:

"Ya se trate de comendadores o compañones (...) o de freires conventuales o integrantes del séquito de dignidades superiores, todos ellos combatían con un equipo completo que venía a consistir, al menos, en dos monturas -un dextrero o caballo acorazado y otra menor utilizada como recua de transporte- $y$ en un equipo humano compuesto por otro combatiente a caballo y dos o tres peones" 28 .

\footnotetext{
Ladero Quesada, Castilla y la conquista..., pp. 30-31.

25 Al decir: "personas implicadas", no especifica si combatían o servían -función logística-. LADERO QUESADA, "La organización militar de la Corona de Castilla en la Baja Edad Media", p. 32; "La organización militar de la Corona de Castilla durante los siglos XIV-XV”, p. 223 [nueva versión].

26 LAdERo Quesada [correo electrónico 1 febrero 2020, en respuesta a mi consulta de 30 enero 2020].

27 Ayala Martínez, Las órdenes militares hispánicas..., p. 555.

28 Ayala Martínez, "Participación y significado de las Órdenes Militares...”, p. 162.
} 
Como antes señalamos, la referencia documental de 1274 establece una cifra concreta de personal a aportar por las encomiendas: un freire, dos "de cavallo" - no precisa si debían ser hombres de armas o jinetes, aunque es probable que se tratara de caballería villana-, y cinco peones, de los que desconocemos sus funciones al no mencionar si llevaban armas y de qué tipo eran, siendo imposible discernir entre guerreros y sirvientes -con actividades logísticas-. Al finalizar el viaje y llegar al punto de reunión, este colectivo dispar se dividiría para formar auténticos grupos de combate. Los peones quedarían bajo el mando de cuadrilleros designados al efecto; los freires y resto de la caballería permanecerían a las órdenes de sus comendadores; y el personal de servicio mantendría su adscripción habitual ${ }^{29}$. Así pues, no encontramos indicios que permitan inferir que el "equipo" formado por dos caballeros y dos o tres peones, propuesto en base al manuscrito de 1274, pueda guardar relación con la lanza.

Aun obviando a los peones, y centrándonos solo en los elementos montados, tampoco vemos factible la propuesta del profesor Ayala Martínez, que sugiere luchen en la misma lanza, dos caballeros juntos, o un caballero y otro combatiente a caballo ${ }^{30}$. Esta posibilidad, aunque viable en lo táctico — brindar apoyo mutuo por vínculos de amistad, fidelidad, dependencia, etc. - , no se corresponde en lo organizativo con los documentos conocidos sobre la lanza castellana, donde no consta que formen Unidad o agrupación militar, como sostiene el autor ${ }^{31}$.

Haciéndose eco de las propuestas de los profesores Ladero y Ayala, otros autores han aplicado diversos factores multiplicadores a la lanza. Jorge Saiz la duplica para 1378-9; Barquero Goñi usa un porcentaje medio de cuatro hombres por lanza; y para la segunda mitad del XIV, Arias Guillén la fija en dos caballeros y dos o tres peones ${ }^{32}$.

Un dato que puede haber servido para sustentar esta postura, sería la errónea interpretación de un pasaje de la Crónica de Juan II: "llevó consigo [Martín Enríquez] cinqüenta lanzas, que sería docientos é cinqüenta de caballo"33, sin tener en cuenta de que no se refiere a lanzas castellanas, sino a "lanzas de ordenanza" francesas, de las que este personaje era capitán.

\footnotetext{
29 Entre los alcantarinos se permitía: "al freire morador que touiere vna bestia o dos que tenga dos omes". Palacios Martín, Colección diplomática..., vol. 1, p. 287 [doc. 434 de 24/06/1306]. En los santiaguistas, por los establecimientos de Mérida de 1403, sabemos que a cada freire le acompaña un sirviente en sus traslados. En concreto, durante la celebración del cabildo en Uclés, los comendadores debían dar: "a cada uno de los dichos freyles raçion doblada por asy e çenzilla para vn moço", -que se supone le asistía-. Carrasco García, "Un modelo monárquico legislativo...,", p. 59.

30 Ayala Martínez, Las órdenes militares hispánicas..., p. 542.

31 “lanza -unidad operativa de combate- (...); 'lanza', entendida ésta como unidad táctica de carácter militar". Ayala Martínez, "Bienes y rentas de las Órdenes Militares...,, pp. 8-10 [nota 6]. No debemos olvidar que toda estructura u organización militar tiene una clara finalidad operativa.

32 SAIZ, Jorge, "Una clientela..., pp. 119, 130. BArquero GoÑI, "La logística de las Órdenes Militares...", p. 28. Arias GuILlÉn, Guerra y fortalecimiento..., p. 122; “Late Middle Ages...”, p. 99.

33 Pérez de Guzmán, "Crónica del rey Don Juan Segundo”, vol. 2, p. 618 [año 1444]. Palacios Ontalva lo cita, pero el detalle le pasa inadvertido. Palacios Ontalva, “Una aproximación...”, p. 315.
} 
Un ejemplo del riesgo de aplicar factores multiplicadores a la lanza lo vemos en el trabajo de González Lanzarote sobre la batalla del Salado en 1340 - fecha en la que aún no consta el concepto-, al fijarla en "cinco hombres y cuatro animales", y presentando cifras desorbitadas ${ }^{34}$.

Por su parte Palacios Ontalva, aunque se inclina al final de su estudio "por asimilar cada lanza a un solo caballero", insiste en hablar a lo largo del mismo de la lanza, como si se tratara de una "Unidad" organizativa, táctica o militar ${ }^{35}$.

Otro detalle que afecta a la composición de la lanza castellana es la montura. Aparte del caballo principal, el profesor Ladero Quesada recordó que el hombre de armas: “debía tener además otro ('dobladura' o 'hacanea') para transportar cargas o sustituir al primero" "36. Creemos necesario matizar su uso. Si se pretende que ese segundo caballo llegue fresco al campo de batalla, lo razonable es emplear bestias de carga para transportar la impedimenta y equipo. De hecho, en el Ordenamiento de Juan I sobre alardes, caballos y mulas de 1390, se estipula: "Que cada vno de los dichos nuestros vasallos trayan sus armas conplidas dela guisa: dos bestias, vn cavallo o coser buenno e vna mula o facanea"37. Y al mencionar este fecho de las lanzas, el cronista López de Ayala lo reitera: "lanzas Castellanas (...), bien encabalgadas (...), é oviese cada lanza dos cabalgaduras, que la una fuese caballo bueno, é la otra mula, ó rocin, ó haca, como mejor pudiese (...). Otrosí (...) que en el Andalucía oviese (...) Ginetes, é que oviese cada uno dos rocines"38. En ambos casos, la finalidad de esa mula, rocín o jaca es evidente. De hecho, aunque no figurase entre las aportaciones obligatorias para servir por parte del hombre de armas - y del jinete frontero andaluz - la carga - equipo y material de vida y acampada-, tras largas marchas, mermaría físicamente dicha dobladura, y de poco serviría como caballo de refresco o sustitución del principal. También es lógico pensar que esa dobladura fuera la montura habitual del paje de lanza ${ }^{39}$; de hecho se convirtió en norma, como refleja el conde de Clonard en relación al Decreto de 2 de mayo de 1493 de creación de las Guardas de Castilla: "Cada hombre de armas tenía dos caballos (...), y el otro llamado dobladura que montaba un paje de lanza" ${ }^{40}$; si bien aquí ya hay un tren logístico de Unidad, que transporta los suministros y el material de campaña, no siendo necesarios más animales de carga. Otras evidencias verifican la realidad castellana: en el alarde de Juan Ponce de León de 1485, los caballeros o

\footnotetext{
34 González Lanzarote, "Batalla del Salado (30 de octubre de 1340)”, pp. 109-110, 119.

35 Palacios Ontalva, "Una aproximación...", pp. 306, 311, 316, 318, 320 [lanza como Unidad], 320 [cita final].

36 LAdero Quesada, Castilla y la conquista..., p. 31.

37 RAH, (ed.), Córtes de los antiguos reinos..., 1863, vol. 2, p. 462 [Juan I. Guadalajara, 1390].

38 López de Ayala, "Crónica del rey Don Juan Primero", vol. 2, p. 132.

39 Ese paje montado llevaría las riendas de la acémila que acarreaba la impedimenta logística. Los hechos de armas citan a los pajes de lanza, como el que asistió en 1452 al condestable Álvaro de Luna en Briones: "E tiráronle de la villa (...) fué ferido junto con él el caballo en que venía un paje suyo con una lanza". Crónica de Don Álvaro de Luna..., p. 293.

40 Sotтo, Historia orgánica de las armas de infantería y caballería..., vol. 2, p. 261. Como señalamos en el texto, el paje de lanza quedaría liberado de llevar otro animal de carga, pues el bagaje lo trasladaría el tren logístico de la Capitanía.
} 
escuderos van solos, o acompañados de un paje como máximo ${ }^{41}$; y en el memorial de servicios de los Orbaneja de Jerez, aparecen testimonios en los que el titular acude con otro - hijo, hermano o criado-, que cabalga a lomos de esa segunda montura con la que está obligado a participar ${ }^{42}$.

Para cerrar este apartado, proponemos matizar otro apunte del profesor Ladero Quesada, en relación a la lanza francesa o borgoñona: 'En Castilla, por el contrario, la 'lanza' apenas existe en el siglo XV"43. A finales del siglo XIV se intenta acrecentar el número de efectivos y mejorar su calidad. Juan I aborda el problema en las Cortes de Briviesca —1387- y Guadalajara - 1390 - y promulga el Ordenamiento de lanzas para alcanzar las seis mil. López de Ayala discrimina la cifra: "quatro mil lanzas castellanas (...) en el Andalucía oviese mil é quinientos ginetes" ${ }^{\text {"4 }}$. En 1391 — minoría de Enrique III-, se prohíbe elevar la cifra ${ }^{45}$. En suma, se pretende buscar un equilibrio entre necesidades militares y posibilidades económicas. Para el siglo XV, los datos sobre alardes y grandes concentraciones -que deben tomarse con las habituales reservas-, no dan impresión de escasez — vid. el cuadro 1, donde la media ronda las 4.000 lanzas-.

Consideremos ahora las lanzas en su cometido de guardia personal. Sabemos que al morir Enrique III en 1406, había tres capitanías - 100 lanzas cada una- para protección de la Corte ${ }^{46}$. Aumentan a más de 1.000 en 1420 que, por quejas de los procuradores, Juan II reduce a 300 en 1429 , y poco después a $100^{47}$. Se incrementan de nuevo con Enrique IV hasta las 3.600 lanzas de hombres de armas y ginetas ${ }^{48}$. Y todos estos datos los maneja y presenta el profesor Ladero en otros trabajos.

\footnotetext{
41 Memorias de Don Enrique IV de Castilla, Colección diplomática, vol. 2, pp. 160-205 [doc. 59].

42 SÁnchez SAus, "La frontera en la caracterización de la aristocracia andaluza...", pp. 283-314.

43 Ladero Quesada, Castilla y la conquista..., p. 31. En otros trabajos dice: "la relativa escasez de caballería pesada se explica por lo raras que eran las batallas campales - muy pocas después de la del Salado en 1340 - tanto como por la eficacia de la carga de caballería en otros tipos de operaciones mucho más frecuentes". Ibidem, "La organización militar...", 1989, p. 24 [nueva versión, 1993, p. 212].

44 López De Ayala, "Crónica del rey Don Juan Primero", vol. 2, pp. 132-133.

45 "Otrosy non acreçentarán mas las lanças (...), de las que estan ordenadas, que son quatro mill lanças castellanas e mill e quinientas de ginetas". RAH, (ed.), Córtes de los antiguos reinos..., 1863, vol. 2, p. 488.

46 Pero Niño era capitán de una. Díaz de Games, El Victorial, pp. 373-374.

47 Pérez de Guzmán, "Crónica del rey Don Juan Segundo", vol. 2, pp. 404, 411, 436.

48 Enríquez del Castillo, "Crónica del rey Don Enrique el Cuarto", vol. 3, p. 110.
} 


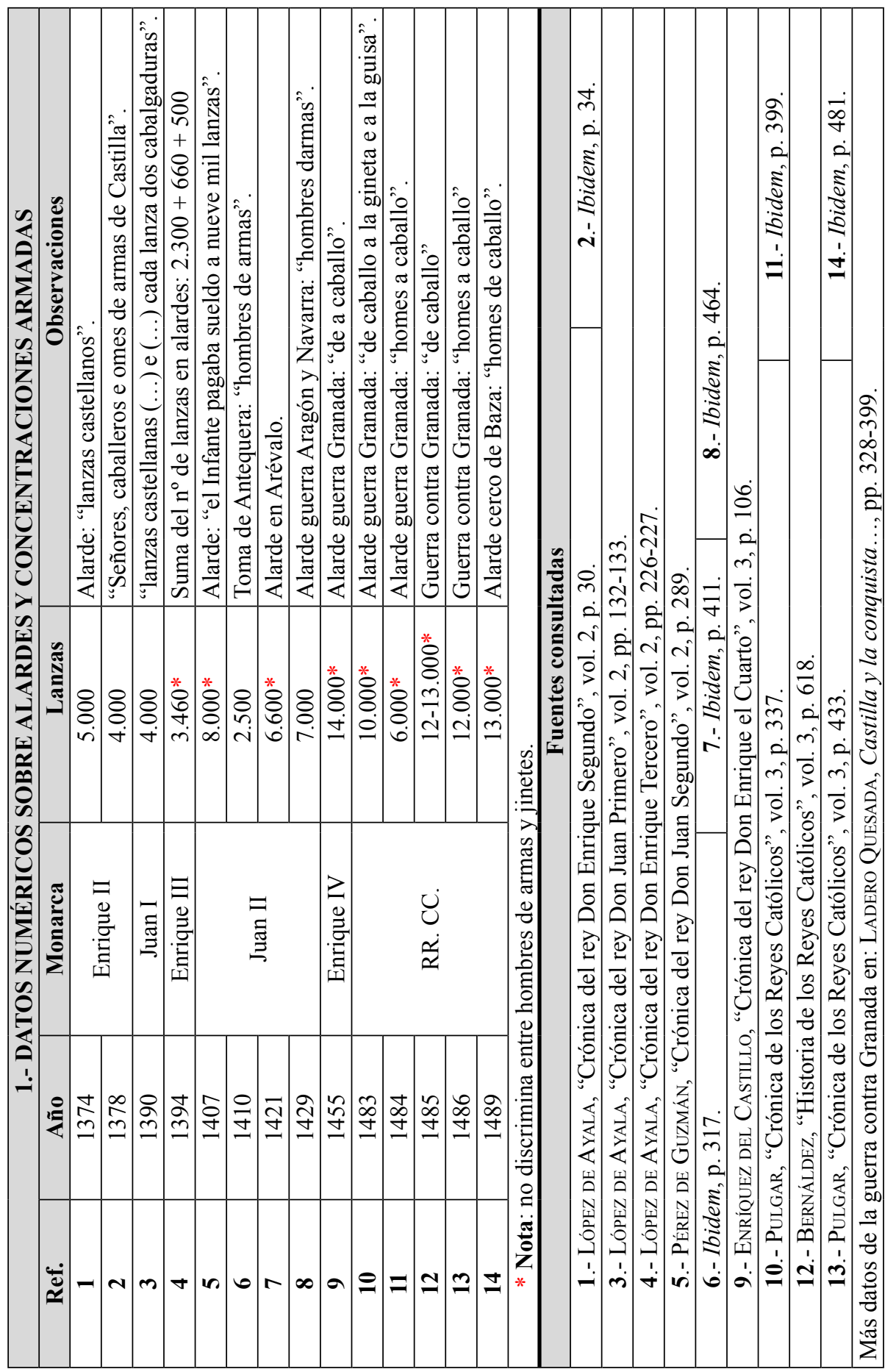




\section{La lanza: ¿Concepto basado en la modificación del armamento y equipo?}

La Crónica Abreviada de López de Ayala para el reinado de Pedro I, hace referencia al retorno de las compañías extranjeras — sobre todo las de Beltrán Du Guesclin一, a sus lugares de origen, a raíz de la guerra civil mantenida entre Pedro I y su hermanastro Enrique de Trastámara, entre 1366 y 1369:

"E a todos estos dixeron en las partidas de Castilla de la Gente blanca; ca ay comenzaron las armas de bacinetes, é piezas, é cotas, é arnés de piernas é brazos, é glaves, é dagas, é estoques; ca antes otras usaban, perpuntes, é lanzas é capellinas; é antes decían omes de caballo, a daqui comenzaron tantas lanzas" ${ }^{49}$.

El texto deja entrever la posibilidad de que el nuevo concepto guarde relación directa con las armas y equipo que, en lo sucesivo, deberán portar los combatientes a caballo, y de forma especial, los denominados "hombres de armas".

Aunque este párrafo no figura en ediciones más actuales de la Crónica de dicho rey ${ }^{50}$, no es difícil comprobar en otras fuentes, que lo dicho en él se ajusta a la realidad.

Los datos del cuadro 2, que exponemos seguidamente, han sido extraídos principalmente de los Ordenamientos de Cortes. Más concretamente, y para los reinados de Pedro I y Enrique II, de los Ordenamientos de menestrales y posturas, donde se tasa el precio a cobrar por producir cada objeto en cuestión.

En efecto, a la vista del cuadro, advertimos que Pedro I regula en 1351 las cantidades a pagar por la confección de capellinas y bacinetes, y obliga en 1364 a todos los que alcancen determinada cuantía, a que el bacinete forme parte de su equipo militar, como consta en el documento emitido por su cancillería real al reino de Murcia.

9 López de Ayala, "Crónica del rey Don Pedro", vol. 1, p. 537 [nota 2].

50 López de Ayala, Crónica del rey Don Pedro y del rey Don Enrique..., vol. 2, p. 119. 


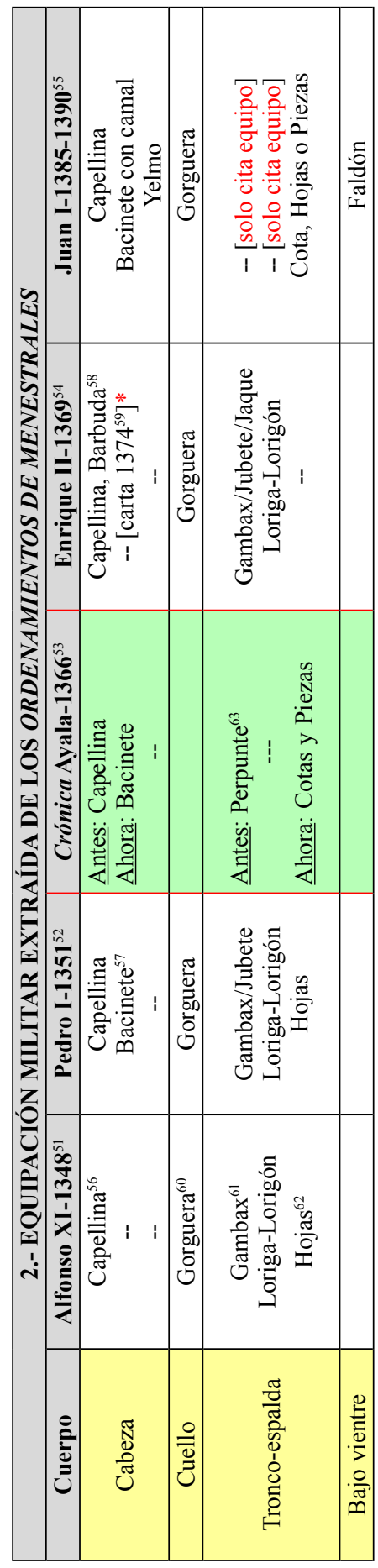

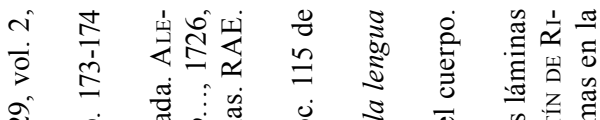

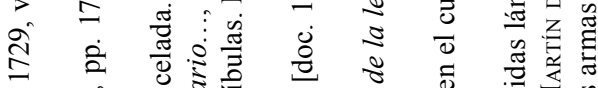

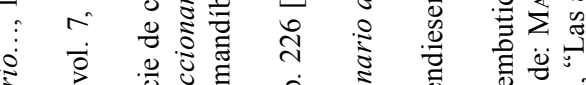

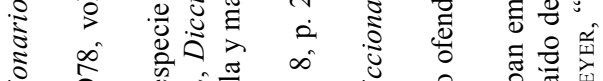

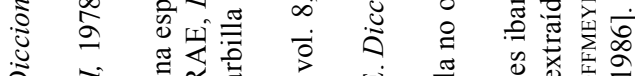

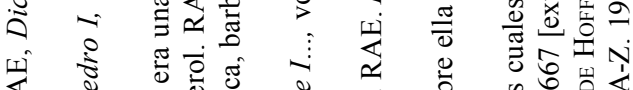
¿ ¿

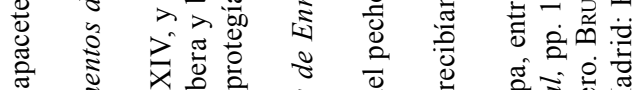

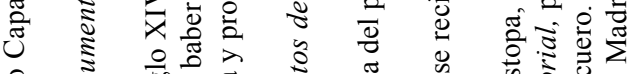

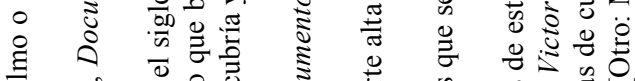

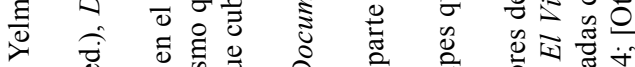
@ 巳

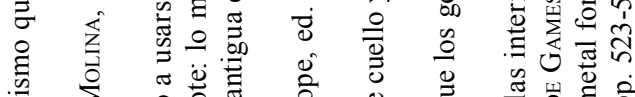

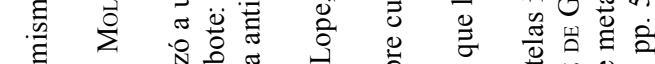

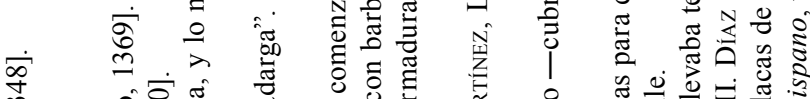
茫 航

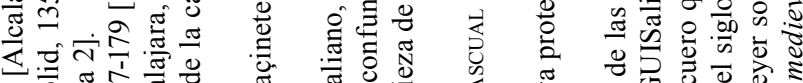

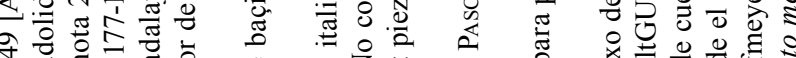

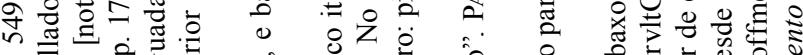

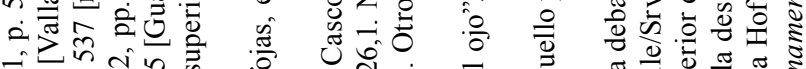

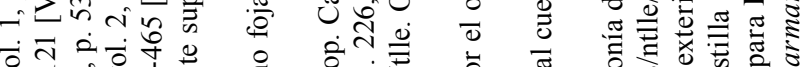

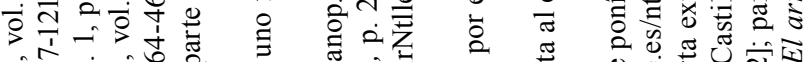

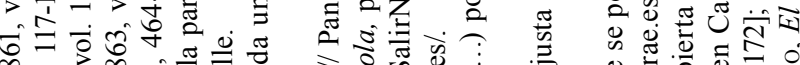

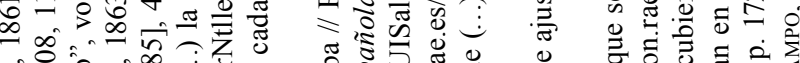

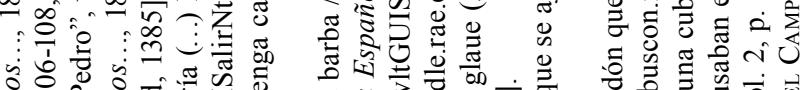

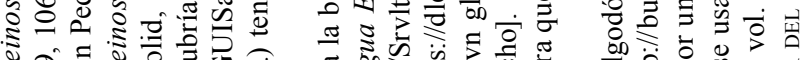

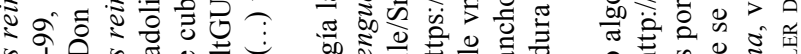

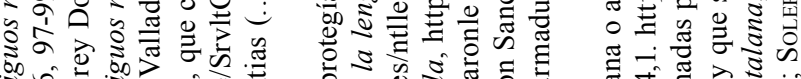
ڤั

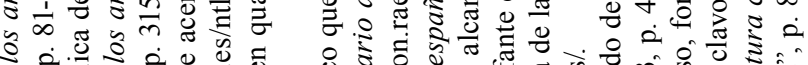
ஓ

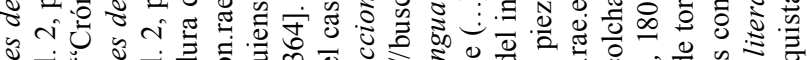

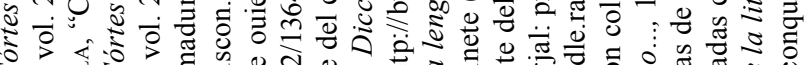
ن

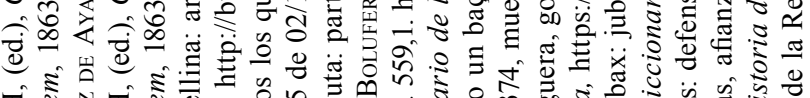

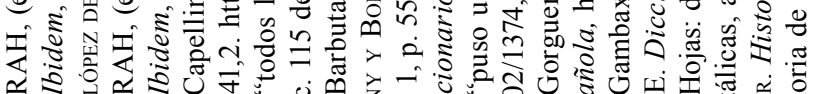

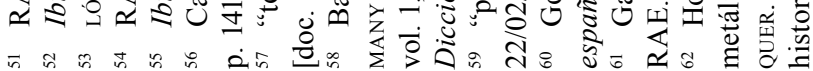



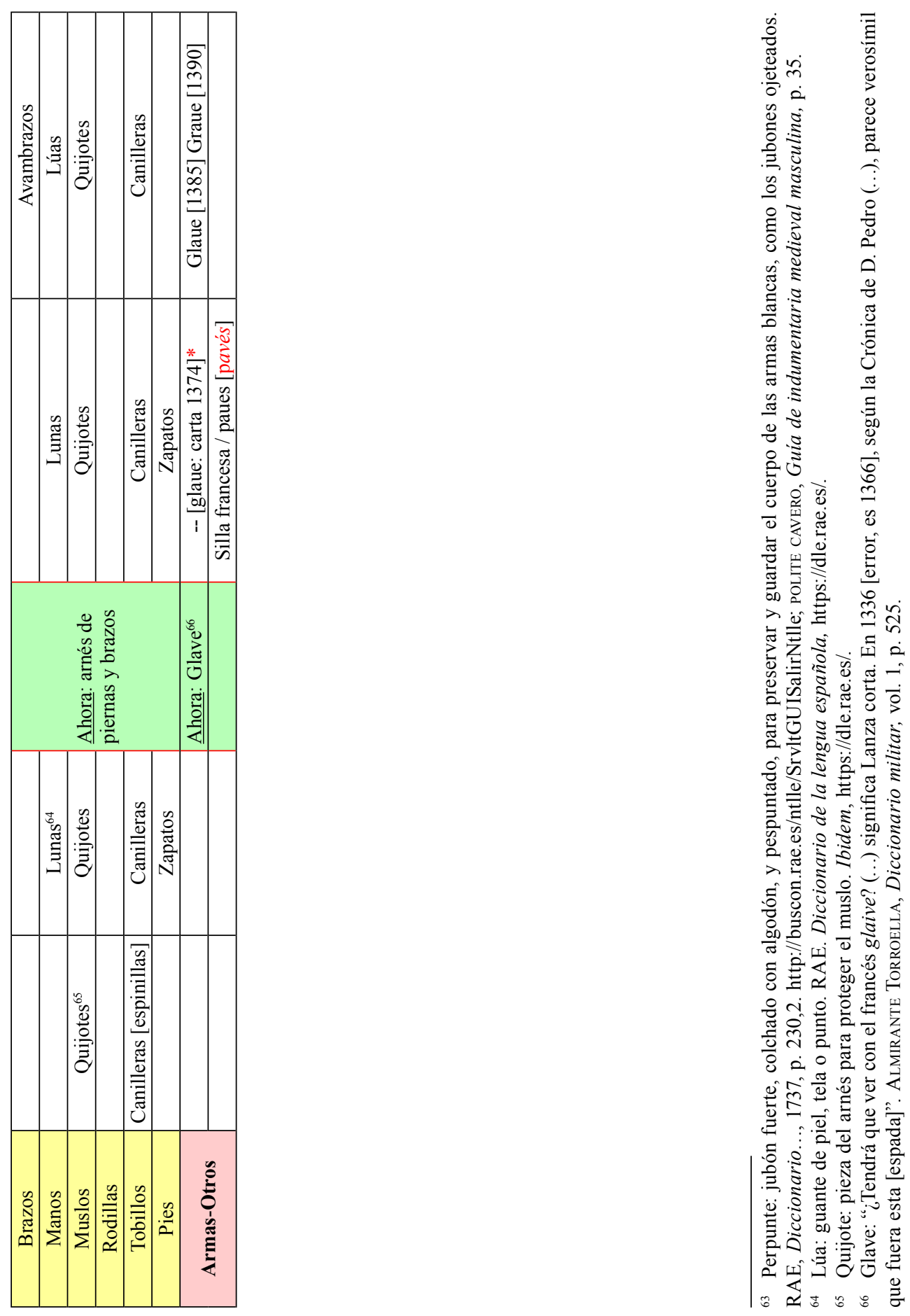
En segundo lugar, encontramos el perpunte — jubón acolchado-, ahora sustituido por las cotas, hojas o "fojas" — defensas de torso con láminas embutidas, que se venían usando desde tiempos de Alfonso XI-, o por piezas con su faldón — placas de metal-, junto con otras para proteger piernas y brazos. Elementos empleados en la guerra Trastámara ${ }^{67}$, y que según reflejan los Ordenamientos de Juan I, serán preceptivos como parte del "arnés cumplido".

Por el orden en que lo narra la Crónica de Ayala: "glaves, é dagas, é estoques", el glave podría considerarse un tipo de espada; de hecho, las fuentes francesas de la época diferencian claramente el glaive de la lanza ${ }^{68}$; aunque a partir del siglo XV, su nombre se usó para designar un arma enastada, similar a la pica ${ }^{69}$. No obstante, resulta significativo que el glave, citado solo dos veces por la Crónica de Ayala, no vuelva a ser mencionado en ninguna otra.

Otro detalle a destacar es la regulación de precios para menestrales en la confección de sillas "francesas" y paveses, que aparecen a partir de 1369 en el Ordenamiento de Enrique II, siendo llamativo que no se vuelva a citar el pavés hasta 1371 —en las crónicas aragonesas ${ }^{70}$ - y finales de 1406 - en las castellanas ${ }^{71}$ -

En definitiva, y basándonos en los antecedentes expresados, sostenemos que las fuentes sugieren la implantación de importantes modificaciones en armas y equipo a raíz del concurso de fuerzas extranjeras en la guerra civil entre Pedro I y Enrique II.

\section{Paralelismos cronológicos}

Incidiendo en la Crónica Abreviada de López de Ayala, destaca el paralelismo cronológico entre la fecha - 1366 - que fija su autor: "a daqui comenzaron tantas lanzas", y la frase del cronista florentino Filipo Villani sobre las Compañías blancas inglesas, al servicio de Pisa en 1363: "i primi che recarono in Italia il conducere la gente di cavallo sotto nome di lance" ${ }^{\text {"72 }}$. También destaca la fecha del contrato -08/12/1367-, suscrito

\footnotetext{
67 Basándose en el códice escurialense, Soler sitúa la aparición del arnés completo en 1350, pero admite que su adopción arrancaría con la guerra Trastámara. SOLER DEL CAMPO, La evolución del armamento medieval..., p. 174.

68 "on parle de bassinets, de lances ou de glaives, de haches et de jaques". Croniques de sire Jean Froissart, vol. 1, p. 58 [año 1337].

69 Laking, A record of European Armour and Arms through seven centuries, vol. 3, pp. 105-107.

70 En referencia al contrato de compañías inglesas para sofocar la rebelión de Cerdeña [desarrollamos abreviaturas]: "peones que llamauan bergantes con coraças, y bacinetes, y con paues, lança y espada". ZuRITA, Los cinco libros postreros..., 1610, vol. 1, Libro X, fol. 361r. Gago-Jover cita la voz para 1385, en la Grant crónica de Espanya I, fol. 528v2. GAGo-Jover, Vocabulario, p. 270.

71 López de Ayala, "Crónica del rey Don Enrique Tercero", vol. 2, p. 261 [doc. a Procuradores, 15/12/1406].

72 "los primeros en traer gente de a caballo a Italia bajo en nombre de lanza" [trad. propia]. VILLANI, Croniche..., vol. 2, p. 401. Citado en: CAFERro, "The fox and the lion...", p. 189; "Edwar Despenser...", pp. 90-91; "The florentine army...", p. 142.
} 
entre autoridades florentinas y el inglés Oschino Arciere para mandar una lanza — primer acuerdo conocido donde figura dicho término en Italia- ${ }^{73}$.

\section{Agrupaciones de lanzas jinetas y castellanas}

La realidad castellana imponía la regulación de todo tipo de monta armada, pero en Andalucía y Murcia se constata un hecho concreto y plenamente consolidado: la monta a la jineta ${ }^{74}$. Esta singularidad, propia de la lucha entre castellanos y nazaríes, generó una serie de procedimientos tácticos ${ }^{75}$ desconocidos entre las fuerzas extranjeras, en particular, entre las compañías inglesas y francesas contratadas para participar en los múltiples enfrentamientos entre facciones petrinas y enriqueñas desde 1366 a 1369 .

Esta necesidad fáctica obligaba a plasmar en la normativa oficial los dos tipos monta castellana: la de la brida o guisa, y la de la jineta, forzando a legislar dotaciones distintas en armas y equipo para cada caso $^{76}$.

\subsection{La lanza jineta}

Como señalamos, al ampliarse el concepto de lanza para Andalucía y Murcia, fue preciso diferenciar ambos tipos, y por ello leemos términos como: hombres de armas y lanzas castellanos por un lado, y lanzas ginetas o ginetes, por otro. Aunque es común en las crónicas el uso de voces como: "lanzas", "cavalgaduras", "rocines", "de caballo"77, que impiden discriminar los tipos y cuantificar los datos ${ }^{78}$.

La gineta debe entenderse como imitación de la monta que adoptaron los nazaríes de los bereberes cenetes $^{79}$, y que a su vez asimilaron los castellanos andaluces, al ser la más idónea al tipo de terreno y forma de combate que imponía la guerra de frontera. Esa experiencia adquirida por los jinetes castellanos se trasladará a otros escenarios bélicos.

\footnotetext{
73 Antes fue capitán -conestabile- de una bandera de 16 hombres a caballo, y en 1369 de 12 lanzas. CAFErro, "Edwar Despenser...", pp. 88, 90, 93; "The florentine army...", pp. 143, 145.

74 Ej.: "muchos caballeros (...) jugaban a la gineta”. "Crónica del rey Don Alfonso el Onceno”, vol. 1, p. 204.

75 Martín Vera, “Tácticas terrestres en la Castilla bajomedieval, siglos XIV-XV”, pp. 118-120.

76 RAH, (ed.), Córtes de los antiguos reinos..., 1863, vol. 2, pp. 315 [Valladolid, 1385], 464-465 [Guadalajara, 1390]. "Los Castellanos eran, según parece, hombres de armas de Castilla, esto es, armados de todas las armas, con estribos largos; y los Ginetes, caballería Andaluza, más ligera (...), con estribos cortos, y armados con lanza y adarga". López dE AyAla, "Crónica del rey Don Pedro”, vol. 1, p. 515 [glosa del editor para 1362].

77 Ej.: "ochocientos hombres de armas é ginetes"; "hasta tres mil rocines, así hombres de armas como ginetes"; "que serían todos cinco mil de caballo entre ginetes é hombres de armas". PÉreZ DE GuZMÁN, "Crónica del rey Don Juan Segundo", vol. 2, pp. 307 [1 $1^{\mathrm{a}}$ cita], 495 [2 $2^{\mathrm{a}}$ cita], 586 [3 $3^{\mathrm{a}}$ cita]. Sobre la voz jinete y sus variantes, vid.: MAíllo SAlgado, “Jinete, jineta y sus derivados...”, p. 105-117.

78 Pensamos que emplean términos ambiguos, al desconocer las cifras concretas de cada tipo.

79 Este tipo de monta: "fijó una verdadera tipología y adiestramiento en las armas (espada ancha, lanza y adarga, cota, borceguíes y espuelas y además estribos cortos)”. Froissart, Crónicas, p. 406.
} 
Y será ese modelo de caballería ligera, el que paulatina pero inexorablemente, acabe prevaleciendo tras los excelentes resultados conseguidos en las guerras de Nápoles ${ }^{80}$.

\subsection{Agrupaciones}

En muchas ocasiones se producen combates donde intervienen, dentro del mismo bando, hombres de armas y jinetes. Obviamente, las peculiaridades en el tipo de monta y el diferente armamento de cada uno, satisfacen necesidades tácticas distintas. Para las contundentes cargas a caballo, el hombre de armas porta un equipo pesado y monta un caballo o coser [corcel] bueno ${ }^{81}$, que suele estar "armado" con cubierta de loriga y yelmo ${ }^{82}$, mientras el caballo del jinete, al no llevarlo, puede ser entrenado en la monta a la jineta, para evolucionar veloz y ágilmente, y escaramuzar "picando de rodeo, unas veces acometiendo y otras huyendo con grande ligereza" ${ }^{\text {" }}$. Por lo tanto, mientras la caballería pesada emplea solo la carga, la jineta se vale fundamentalmente del tornafuy y la escaramuza para sus maniobras.

El arma principal, la lanza, también es diferente. La "lanza de armas" que llevaba el hombre acorazado - denominada así por fuentes documentales, como los inventarios de armerías y arsenales de fortalezas y castillos ${ }^{84}$, aunque de mayor longitud, era ligera de peso ${ }^{85}$. Una muestra de la ineficacia de estas largas lanzas cuando su portador es descabalgado, la ofrece la crónica lusa al tratar el episodio de la batalla de Aljubarrota -1385-, y asegurar que los hombres de armas castellanos debieron quebrar sus lanzas para acortarlas y usarlas en el combate cuerpo a cuerpo ${ }^{86}$. En cuanto a las dimensiones y uso de la lanza jineta, un documento de sumo interés, aunque algo tardío, es el Tratado

\footnotetext{
80 "En las tierras del S., y paulatinamente en toda la Corona durante el siglo XV, predominó o creció la importancia de la caballería ligera 'a la jineta', de origen y tradición musulmanes, mucho mejor adaptada para una guerra de algaradas, sorpresas, vigilancia y lucha contra grupos de infantería en zonas montañosas”. Más adelante se añade: “pero el futuro sería mucho más favorable, así se demostró ya en las guerras de Nápoles, a las formaciones de caballería ligera”. LAdero QuesadA, "La organización militar...”, 1989, p. 24 [nueva versión, 1993, pp. 212-213].

81 RAH, (ed.), Córtes de los antiguos reinos..., 1863, vol. 2, p. 462 [Ordenamiento sobre alardes, caballos y mulas. Juan I. Guadalajara, 1390].

82 En la batalla de Nájera, 1367: "iban muchos caballos armados”, en concreto: "el Rey Don Enrique llegó (...) en su caballo armado de loriga”. LóPez DE AYALA, “Crónica del rey Don Pedro”, vol. 1, pp. 552, 557. En la $2^{\text {a }}$ batalla de Olmedo -1467-, el caballo del duque de Alburquerque llevaba: "cubiertos el cuello é testera". VALERA, "Memorial de diversas hazañas", vol. 3, p. 42. Y sabemos los precios por acicalar lorigas y yelmos de caballos. RAH, (ed.), Córtes de los antiguos reinos..., 1863, vol. 2, pp. 81, 97, 107, 119 [Pedro I. Valladolid, 1351]; 178 [Enrique II. Toro, 1369].

83 RAE. Diccionario..., 1732, vol. 3, p. 555, 2. http://buscon.rae.es/ntlle/SrvltGUISalirNtlle. Sobre la variedad morfológica de las cabañas equinas, vid., Nogales Rincón, "La monta a la jineta...", p. 46.

${ }^{84}$ Lora Serrano, "La organización de la defensa de un estado sensorial...”, pp. 318, 326. Franco SiLva y Soler del CAmpo, "Los arsenales de dos fortalezas castellanas...”, pp. 331, 337, 339. Franco Silva, "Armas y pertrechos militares de seis fortalezas...," p. 203.

${ }_{85}$ "Lanzas de armas: La que usaba el hombre de armas. Era de fresno, muy ligera, de 18 palmos, y el hierro de figura de hoja de oliva". D’WARTELEt, Diccionario Militar, p. 463.

${ }^{86}$ Lopes, Chronica de El-Rei D. João I, vol. 4, p. 166.
} 
de Cavallería de la Gineta, de Pedro de Aguilar, que detalla no solo su longitud ideal -entre 16 y 18 palmos $^{87}$-, sino también la forma de llevarla y combatir con ella ${ }^{88}$.

Y en relación a esto último, conviene decir que ambos — hombres de armas y jinetes-, pueden "cargar" con sus lanzas, como lo expresan las crónicas: debajo del brazo y con la mano puesta para enristrar, o sea, "so los sobacos" o "en los ristres". Para no confundirnos al leer textos de la época, hemos de aclarar que el término enristrar, aparte de su significado usual - poner o fijar la lanza en el ristre-, tiene otra acepción, ésta en sentido figurado, entendida como la forma de poner la lanza bajo el brazo, enderezando su punta hacia el pecho del contrario ${ }^{89}$.

Además de estas lanzas, los jinetes suelen portar otras más cortas y ligeras, de tipo arrojadizo: azagayas, dardos y venablos, llamadas también azconas, y usadas así mismo por los peones ${ }^{90}$.

Cuando las fuentes hablan de enfrentamientos entre hombres de armas y jinetes, los textos castellanos tienden a ensalzar la monta a la guisa ${ }^{91}$, pero esta visión es interesada y cuestionable, pues ambas facciones intentan siempre contar con los dos tipos de monta entre sus filas; eso sí, en formaciones distintas y con jefes encabalgados conforme al grupo liderado. Se busca combinar la potencia de choque al frente de los haces de caballería pesada, con tropeles de jinetes a los flancos, con el fin de neutralizar las penetraciones por los costados y las acciones envolventes. Tal como desplegaron ambos bandos en liza, al iniciar la batalla de Olmedo $-1445-^{92}$. Tampoco debemos descartar

\footnotetext{
87 También indica otros tamaños, como el de las lanzas comunes -entre 17 y 20 palmos-, y el de las más largas -de 20 a 30 palmos-. Agullar, Tractado de cavallería a la gineta, pp. $37 \mathrm{v}$ [ideal], 38 v. [común y muy largas]. Palmo: unos $20 \mathrm{~cm}$. RAE. Diccionario de la lengua española, https://dle.rae.es/.

88 Correr con la lanza en el hombro o atravesada, y ponerla de encuentro: junto a la cintura o debajo del brazo. Aguilar, Tractado..., pp. 36 r-40 r [con y sin adarga]. También trata las formas de atacar y recibir con espada y capa, de frente y revés -tajo, revés y estocada-, parando, pasando o volviendo. Ibidem, pp. $40 \mathrm{r}-41 \mathrm{v}$.

89 Esta segunda acepción figura en los diccionarios históricos: RAE. Diccionario..., 1780, p. 410,2. http:// buscon.rae.es/ntlle/SrvltGUISalirNtlle. Y en los militares: Almirante Torroella, Diccionario militar, vol. 2, p. 704. Y así nos lo aclara el tratadista Pedro de Aguilar. Aguilar, Tractado..., p. 38 r. Por eso, siempre que analicemos textos cronísticos, debemos tenerlo presente. Como en el enfrentamiento entre lanzas cristianas y nazaríes, en 1410: "E los cristianos (...), boluieron a los moros muy de rezio, las lanças so los sobacos. Los moros echaron las lanças en los ristres". GarCía de SANTA María, Crónica de Juan II, 1982, p. 386. O en este otro segundo ejemplo temprano, donde en el Victorial se relata un famoso encuentro acaecido entre 1435-6: "E don Juan puso las espuelas al cavallo, e una fuerte lança en el ristre, e fuelos ferir". Díaz de Games, El Victorial, pp. 431-432 [texto], 433 [fecha]. Aquí sí consideramos que se refiere a la colocación de la lanza en su ristre. Ristre: "hierro que el hombre de armas ingiere en el peto, a la parte derecha, donde encaja el cabo de la manija de la lanza, para afirmar en el". Covarrubias, Tesoro de la lengua..., 1611, p. 1229,1-1229.2. http://buscon.rae.es/ntlle/SrvltGUISalirNtlle.

90 Almirante Torroella, Diccionario militar, vol. 1, pp. 116-117.

91 "porque non andar armados nin encavalgados en guisa que puedan sofrir feridas commo cavalleros nin venir a las manos"; "en la hueste que está asentada nunca ellos se atreven a entrar; nin otrosí, de noche (...) porque non andan armados nin los sus cavallos non andan enfrenados nin ensellados en guisa". JuAN Manuel, El libro de los Estados, pp. 224, 227.

92 Crónica de Don Álvaro de Luna..., p. 167; Pérez de GuzmÁn, "Crónica del rey Don Juan Segundo", vol. 2 , p. 628 .
} 
las intervenciones - no tan coyunturales como se pueda pensar-, de monturas pesadas y ligeras en el mismo grupo de combate ${ }^{93}$.

\section{La lanza como concepto de valor fiscal}

Hay un detalle final por tratar: la vertiente económica. Al quedar cuantificada la lanza en los Ordenamientos reales de Juan I, ésta se convierte en un módulo monetario de valor fiscal. Algo que se venía gestando desde el reinado de Alfonso XI, con sus continuos incrementos de valor en metálico.

\begin{tabular}{|c|c|l|c|}
\hline \multicolumn{5}{|c|}{ 3.- EVOLUCIÓN EN EL PAGO DE ACOSTAMIENTOS REALES } \\
\hline Rey & Año & \multicolumn{1}{|c|}{ Concepto, según el Ordenamiento de Cortes } & \multicolumn{1}{c|}{ Cantidad } \\
\hline \multirow{2}{*}{ Alfonso XI 94} & 1338 & \multirow{2}{*}{ "vn omme acauallo" — aún no se habla de lanza } & $1.100 \mathrm{mrs}$ \\
\cline { 2 - 4 } & 1348 & & $1.200 \mathrm{mrs}$ \\
\hline \multirow{3}{*}{ Juan I 95 } & 1387 & "cada lança” & $1.500 \mathrm{mrs}$ \\
\cline { 2 - 4 } & 1390 & "cada ginete" & $1.300 \mathrm{mrs}$ \\
\cline { 2 - 4 } & & $2.500 \mathrm{mrs}$ \\
\hline
\end{tabular}

A pesar de lo señalado, la documentación estudiada no refleja que estas cantidades otorgadas a sus beneficiarios, se empleen en abonar sueldos a otras personas que les sirvan o acompañen — salvo a los pajes-. En todo caso, de haber existido, debieron correr por cuenta de éstos. El profesor Ladero ya lo indicó: "no conozco documentos fiscales que permitan comprobarla"96, en referencia al número de personal — sobre todo de servicio-, que se sumaría a la lanza castellana.

No obstante, y pese a lo apuntado, el estudio de la perspectiva fiscal, ofrece un amplio y sugestivo abanico de posibilidades a la investigación, como son: indagar las razones que subyacen en el incremento de las cuantías, más allá del aumento de costes o las depreciaciones monetarias; desvelar si el dinero se empleaba efectivamente en lo establecido o se derivaba a otros fines; averiguar hasta qué punto la concesión de mercedes en concepto de mantenimiento de lanzas menoscababa los ingresos de las

\footnotetext{
93 En cabalgadas u operaciones conjuntas, lo usual es usar jinetes de "corredores" o vanguardia, mientras los hombres de armas montan la celada, o forman en batalla. GARCíA DE SANTA MARÍA, Crónica de Juan II, pp. 325, 327, 357-358.

94 RAH, (ed.), Córtes de los antiguos reinos..., 1861, vol. 1, pp. 450 [Burgos, 1338], 548 [Alcalá, 1348].

95 Ibidem, 1863, vol. 2, pp. 392 [Briviesca, 1387], 461 [Guadalajara, 1390].

96 LAdero Quesada [correo electrónico 01/02/2020, en respuesta a mi consulta de 30/01/2020]. Para una visión detallada del origen, evolución y desarrollo de los acostamientos en Castilla, principalmente durante el siglo XV, vid.: Ladero Quesada, Ejércitos y armadas de los Reyes Católicos..., pp. 179-189.
} 
arcas reales ${ }^{97}$; profundizar en el análisis de los mecanismos de fraude ${ }^{98}$ — sus razones, quiénes se benefician, a qué dedican las cantidades defraudadas, etc.- - la cuestión de las duplicidades — servir con las mismas lanzas a varios señores, incluida la Corona-, y los perjuicios que ocasionaban ${ }^{99}$; sopesar el alcance de la percepción de acostamientos librados por la hacienda real, en relación con la formación de redes clientelares señoriales ${ }^{100}$; saber quién abona realmente las nóminas de las lanzas cuando son activadas para el servicio - ¿el rey ${ }^{101}$, los concejos $^{102}$, los señores [luego resarcidos y por quién] ${ }^{103}$, o los propios intervinientes ${ }^{104}$ ? - . Todo ello, sin perder de vista la evolución temporal y las diferentes modalidades de servicio — no tienen la misma consideración, sobre todo en el plano fiscal, la lanza de las guardas personales de monarcas y señores, que la de la Santa Hermandad, o la de las Guardas de Castilla-.

97 Señalado en las peticiones de los procuradores en Cortes ante Juan II: "non dé de nueuo mrs. algunos por juro de heredad nin de merçed por vida nin de mantenimiento nin de rraiçion nin de quitaçion nin de tierra para lanças nin en otra manera a persona alguna, ca poco aprouecharia para conseruacion e aumento de vuestras rrentas". RAH, (ed.), Córtes de los antiguos reinos..., 1866, vol. 3, p. 577 [Valladolid, 1451]. 98 Como reclamaba Enrique III en su misiva a los maestres de las órdenes de Santiago y Alcántara: "que todas las lanças que vos, e los otros mis vasallos que vos aguardan y tenedes, era fasta nueveçientas lanças, et so mucho maravillado desta razón, por quando segund la cuenta que yo acá mandé facer ellas debían ser mille e quatroçientas lanças". Palacios MarTín, Colección diplomática..., vol. 1, pp. 519-521 [doc. 750 de 16/08/1398?]. O el engaño sufrido por el infante don Fernando en el alarde del 28 de agosto de 1407: "pagaba sueldo a nueve mil lanzas, é con todas las faltas no llegaron a ocho mil". PéreZ DE Guzmán, "Crónica del rey Don Juan Segundo", vol. 2, p. 289.

99 "Vos ponedes a un Señor ciento é cincuenta mil maravedís en tierra para cien lanzas, (...); é aquel Señor toma caballeros é escuderos vuestros vasallos en cuenta destas cien lanzas, é dales de acostamiento estos (...) maravedís que le vos dades". López de Ayala, "Crónica del rey Don Enrique Tercero", vol. 2, p. 215 [denuncia de los procuradores en las Cortes de Madrid de 1393]. Aunque las duplicidades estaban tipificadas y penadas: "E qual quier que (...) tomare libramiento de dos sennores ode mas de dos, quelo maten por ello". RAH, (ed.), Córtes de los antiguos reinos..., 1861, vol. 1, pp. 451-452 [Alfonso XI. Cortes de Burgos, 1338]; "quelos caualleros e escuderos (...) non viviesen nin fuesen de ningund cauallero nin de otro señor nin lo sirviesen (...) en qual quier manera nin rresçibiesen dellos tierras nin acostamiento nin otros mrs. nin cosa alguna" [Juan II. Cortes de Valladolid, 1447, petición n $\left.{ }^{\circ} 19\right]$. Ibidem, 1866, vol. 3, pp. 519-520.

100 Redes, usadas también para fomentar el abuso señorial y bandidaje, y que generaron levantamientos populares, como en Galicia. PARdo de Guevara y Valdés, "La revolución hermandiña de 1467", p. 13.

${ }_{101}$ Ladero Quesada, "La financiación de la guerra por la Monarquía...", p. 18.

${ }_{102}$ Los concejos, además de costear el sueldo de los que servían en la Hermandad, también debían erechar. Así lo demuestra la carta de 6 de abril de 1479, enviada por los diputados generales de la Hermandad al concejo hispalense, ordenando que indemnicen al escudero sevillano Cristóbal de Quejo por el caballo y armas perdidas, tras haber sido capturado y permanecer prisionero de los portugueses durante ocho meses. López Martínez, La Santa Hermandad de los Reyes Católicos..., pp. 51-52. Como ejemplo de las prestaciones de los concejos fronterizos andaluces al esfuerzo de guerra, vid.: SÁnchez SAus, "Sevilla y la frontera (1446-1452): una economía de guerra", pp. 133-148.

${ }^{103}$ En 1458, el conde de Arcos abona los sueldos a las lanzas de su Capitanía y gente de su señorío que acudió a su llamamiento. Tras realizar el preceptivo alarde, ordena remitir las cuentas al rey para que se las page. Memorias de Don Enrique IV de Castilla, Colección diplomática, vol. 2, p. 205 [doc. 59]. En el documento figuran las lanzas y jinetes acompañados de "pajes", que lógicamente reciben sus pagas.

${ }^{104}$ Los Orbaneja relatan en su memorial de servicios, dos ocasiones en las que sirvieron a su costa. SÁNCHEZ SAUS, "La frontera en la caracterización de la aristocracia andaluza...”, p. 296. 


\section{Conclusiones}

No pretendemos negar la posibilidad de que existiera el concepto lanza antes de ser documentado, pero si hemos de ceñirnos a lo conocido, tampoco podemos afirmar lo contrario. Y en base a lo constatado, presentamos nuestra propuesta sobre el origen del cambio del concepto "hombre de armas" en Castilla — a pesar de su pervivencia en fuentes cronísticas-, por el de lanza; persuadidos de que esta modificación tiene mucho que ver con la detallada - y a veces novedosa - equipación militar, que en algunos casos se va incorporando progresivamente - bacinete, lunas, etc. - , pero que ahora se exige por ley, en gran medida por el influjo de las compañías extranjeras que intervinieron en la guerra civil entre Pedro I y el futuro Enrique II, y en otras contiendas como la italiana, y no por el número de hombres que la pudieran formar - aspecto que documentalmente no es factible, pues en el caso castellano se trata solo de un hombre de armas y un paje a lo más-, ni porque pueda constituir una Unidad militar de carácter táctico u organizativo — postura que, a nuestro entender, también resulta inviable-.

En tierras castellanas, el elemento nuclear de la lanza es el hombre de armas, que puede ser un miembro de la nobleza, un caballero, un escudero, u otro - cortesano, gentilhombre, etc.- , que cumpla con las condiciones requeridas sobre dotación de armas, equipo y monturas, bien por las nóminas - mrs., tierras, etc.- - recibidas como vasallo del rey u otro señor, o por ser oficial del concejo, o caballero cuantioso de ciudad, villa o lugar ${ }^{105}$. En síntesis, un hombre de armas puede ser caballero y también escudero, y ambos suman dos lanzas castellanas, nunca una ${ }^{106}$.

En cuanto al número de lanzas movilizadas por Castilla desde el último tercio del XIV y hasta finales del XV, los datos cronísticos permiten aventurar la cifra media de 4.000. Cantidad nada desdeñable, habida cuenta las capacidades económicas del reino.

Aclarar la diferencia entre lanzas de hombres de armas y jinetas, fue otro punto que advertimos necesario. A este respecto, hemos aportado datos y argumentado nuestro punto de vista, al objeto de evidenciar que ambas modalidades responden a peculiaridades geográficas singulares y necesidades tácticas concretas.

Finalmente, nos gustaría formular una última proposición: conscientes de las limitaciones de nuestra propuesta, fruto de la escasez documental en la materia y de la necesidad de ampliar el campo de investigación — sobre todo en el plano fiscal, cuyas implicaciones superan el ámbito militar y alcanzan el político y social-, esperamos que este trabajo sirva de acicate a otros historiadores para seguir profundizando en un tema tan relevante como cautivador, del que aún queda mucho por desvelar.

\footnotetext{
${ }^{105}$ Contamine, La guerra en la Edad Media, p. 164; RAH, (ed.), Córtes de los antiguos reinos..., 1863, vol. 2, pp. 392-393 [Juan I. Briviesca, 1387]. Ibidem, 1866, vol. 3, p. 577 [Juan II. Valladolid, 1451]. Si bien hay consenso en considerarlo distintivo del estamento nobiliario: "por esta época el hombre de armas es noble invariablemente". MAíllo SALGAdo, "Jinete, jineta y sus derivados...," p. 113.

106 “él [Enrique II] enviará el su pendón con tres mil lanzas de Caballeros é Escuderos”. LóPEZ DE AYALA, "Crónica del rey Don Enrique Segundo", vol. 2, p. 30.
} 


\section{Bibliografía}

Aguilar, Pedro de, Tractado de cavallería a la gineta, Impr. Iuan René, Málaga, 1600, $2^{\mathrm{a}}$ ed. [ $1^{\mathrm{a}}$ ed., Hernando Díaz, Sevilla, 1572].

Alonso BAquer, Miguel, "Las guerras y su técnica en la época del Renacimiento", Actas de las II Jornadas Nacionales de Historia Militar. La organización militar en los siglos XV y XVI, Cátedra General Castaños, Málaga, 1993, pp. 343-352.

Arias Guillén, Fernando, Guerra y fortalecimiento del poder regio en Castilla. El reinado de Alfonso XI (1312-1350), CSIC, Madrid, 2012.

Arias Guillén, Fernando, "Late Middle Ages (14th to 15th centuries)", Francisco García Fitz y Joao Gouveia Monteiro (eds.), War in the Iberian Peninsula, 700-1600, Routledge, London and Nueva York, 2018, pp. 94-123.

Ayala Martínez, Carlos de, "Participación y significado de las Órdenes Militares en la conquista de Carmona", Actas del I Congreso de Historia de Carmona. Edad Media, Archivo Hispalense, t. 80 (243-244-245), Diputación Provincial, Sevilla, 1998, pp. 147-173. Ayala Martínez, Carlos de, "Bienes y rentas de las Órdenes Militares castellanoleonesas (ss. XII-XIV). Balance y perspectivas de análisis", Aragón en la Edad Media. Rentas, producción y consumo en España en la Baja Edad Media. Sesiones de trabajo. Seminario de Historia Medieval, Universidad de Zaragoza, Zaragoza, 2001, pp. 7-18. Ayala Martínez, Carlos de, Las órdenes militares hispánicas en la Edad Media (siglos XII-XV), Marcial Pons y Latorre Literaria, Madrid, 2007.

BArquero GoÑI, Carlos, "La logística de las Órdenes Militares (siglos XII-XV)", Revista de las Órdenes Militares, 9 (2017), pp. 11-33.

Bernáldez, Andrés, "Historia de los Reyes Católicos", ed. Cayetano Rosell, Crónicas de los reyes de Castilla, BAE 70, Atlas, Madrid, 1953, vol. 3.

Bruhn De Hoffmeyer, Ada, "Las armas en la historia de la Reconquista", Gladius. I Simposio Nacional. Las Armas en la Historia, 1988, pp. 31-101.

Caferro, William P., "The fox and the lion': The White Company and the Hundred Years War in Italy", L. J. Andrew Villalon y Donald J. Kagay (eds.), The Hundred Years War. A Wider focus, Brill, Leiden, Boston, 2005, pp. 179-210.

CAferro, William P., "Edward Despenser, the Green Knight and the Lance formation: Englishmen in Florentine military service, 1366-1370", L. J. Andrew Villalon y Donald J. Kagay (eds.), The Hundred Years War (Part III). Further Considerations, Brill, Leiden, Boston, 2013, pp. 85-103.

CAferro, William P., "The Florentine army in the Age of the Companies of Adventure", Millars: Espai i história, 43/2 (2017), pp. 129-150.

CARrasco García, Gonzalo, "Un modelo monárquico legislativo y jurídico para la Orden de Santiago. El maestre Lorenzo Suárez de Figueroa y los establecimientos de Uclés (1395) y Mérida (1403)", Espacio, Tiempo y Forma (UNED), 24 (2011), pp. 13-68. 
Contamine, Philippe, Guerre, état el société à la fin du Moyen Âge. Études sur les armées des rois de France 1337-1494, Mouton, La Hayre, París, 1972.

Contamine, Philippe, La guerra en la Edad Media, Labor, Barcelona, 1984.

Crónica de Don Álvaro de Luna. Condestable de Castilla y maestre de Santiago, ed. Juan de Mata Carriazo, Madrid, Espasa Calpe, 1940.

“Crónica del rey Don Alfonso el Onceno", ed. Cayetano Rosell, Crónicas de los Reyes de Castilla. BAE 66, Atlas, Madrid, 1953, vol. 1.

Croniques de sire Jean Froissart: qui traitent des merveilleuses emprises, nobles aventures et faits d'armes aventures en son temps en France, Angleterre, Bretaigne, Bourgogne, Ecosse, Espaigne, Portingal et ès autres parties, ed. J. A. C. Buchon, Auguste Desrez (impr.-ed.), Paris, 1840, vol. 1.

DíAz de GAmes, Gutierre, El Victorial, ed., est. y notas Rafael Beltrán, RAE, Madrid/ Galaxia Gutenberg-Círculo de Lectores, Barcelona, 2014.

Enríquez del Castillo, Diego, “Crónica del rey Don Enrique el Cuarto”, ed. Cayetano Rosell, Crónicas de los reyes de Castilla, BAE 70, Atlas, Madrid, 1953, vol. 3.

Franco SiLva, Alfonso, “Armas y pertrechos militares de seis fortalezas señoriales al término de la Edad Media: Oropesa, Jarandilla de la Vera, Cabañas, Villalba, Mejorada y Castilnovo", En la España Medieval, 32 (2009), pp. 193-209.

Franco Silva, Alfonso y Soler del Campo, Álvaro, "Los arsenales de dos fortalezas castellanas: inventarios de Torremormojón (1506) y Pedraza de la Sierra (1512)", Historia, Instituciones, Documentos, 21 (1994), pp. 309-344.

Froissart, Jean, Crónicas, eds. Victoria Cirlot y J. E. Domenech, Siruela, Madrid, 1988. García de Santa María, Álvar, Crónica de Juan II, ed. Juan de Mata Carriazo, Real Academia de la Historia, Madrid, 1982.

González Lanzarote, José María, "Batalla del Salado (30 de octubre de 1340)", O’Donnell y Duque de Estrada (dir.) y A. de la Rosa Morena (coord.), Historia militar de España. Campañas, Batallas y hechos singulares, Ministerio de Defensa, [S.1.], 2017, vol. 5, pp. 103-120.

Juan Manuel, Don, El libro de los Estados, eds. I. R. Macpherson y R. B. Tate, Castalia, Madrid, 1991.

KeEn, Maurice, (ed.), Historia de la guerra en la Edad Media, Machado, Madrid, 2010.

LAdero Quesada, Miguel Ángel, "La organización militar de la Corona de Castilla en la Baja Edad Media", Castillos medievales del Reino de León, S. A. Hullera VascoLeonesa, Madrid, 1989, pp. 11-34.

LAdero QuesadA, Miguel Ángel, "La organización militar de la Corona de Castilla durante los siglos XIV-XV”, La incorporación de Granada a la Corona de Castilla, Diputación Provincial, Granada, 1993, pp. 195-227. 
Ladero Quesada, Miguel Ángel, Castilla y la conquista del reino de Granada, Diputación Provincial, Granada, 1993, $2^{\mathrm{a}}$ ed.

LADERo QuesAdA, Miguel Ángel, "La financiación de la guerra por la Monarquía castellana 1252-1515”, Revista de Historia Militar. 2007 (n extraordinario), pp. 13-38.

Ladero Quesada, Miguel Ángel, Ejércitos y armadas de los Reyes Católicos. Nápoles y el Rosellón. 1494-1504, Real Academia de la Historia, Madrid, 2010.

Ladero Quesada, Miguel Ángel, Correo electrónico de 01 febrero 2020, en respuesta a la consulta de Manuel Ángel Martín Vera, "Saludos y consulta", de 30 enero 2020.

LAKING, Guy Francis, A record of European Armour and Arms through seven centuries, G. Bell and Sons, LTD., London, 1920, vol. 3.

Las Siete Partidas del rey Don Alfonso el Sabio, cotejadas con varios códices antiguos por la Real Academia de la Historia, ed. RAH, Impr. Real, Madrid, 1807, vol. 2.

Lopes, Fernão, Chronica de El-Rei D. João I, Escriptorio, Lisboa, 1897, vol. 4.

López de Ayala, Pedro, "Crónica del rey Don Pedro", ed. Cayetano Rosell, Crónicas de los reyes de Castilla, BAE 66, Atlas, Madrid, 1953, vol. 1.

López de Ayala, Pedro, "Crónica del rey Don Enrique Segundo", ed. Cayetano Rosell, Crónicas de los reyes de Castilla, BAE 68, Atlas, Madrid, 1953, vol. 2.

López de Ayala, Pedro, "Crónica del rey Don Juan Primero", ed. Cayetano Rosell, Crónicas de los reyes de Castilla, BAE 68, Atlas, Madrid, 1953, vol. 2.

López de Ayala, Pedro, "Crónica del rey Don Enrique Tercero", ed. Cayetano Rosell, Crónicas de los reyes de Castilla, BAE 68, Atlas, Madrid, 1953, vol. 2.

López de Ayala, Pero, Crónica del rey Don Pedro y del rey Don Enrique, su hermano, hijos del rey don Alfonso Onceno, ed. Germán Orduna, Secrit, Buenos Aires, 1997, vol. 2.

López Martínez, Celestino, La Santa Hermandad de los Reyes Católicos, Impr. L. Vilches, Sevilla, 1921.

Lora Serrano, Gloria, "La organización de la defensa de un estado sensorial y el potencial bélico de un noble a mediados del siglo XV", Historia, Instituciones, Documentos, 18 (1991), pp. 297-338.

Maíllo Salgado, Felipe, "Jinete, jineta y sus derivados. Contribución al estudio del medievo español y al de su léxico”, Studia Philologica Salmanticensis, 6 (1982), pp. 105-117. Martín de Riquer, Historia de la literatura catalana, Ariel, Barcelona, 1983, vol. 2.

Martín Vera, Manuel Ángel, Los orígenes del Ejército Moderno en el reino de Castilla, siglos XIV-XV [Tesis Doctoral Inédita]. Universidad de Sevilla, 2019, https://hdl.handle. net/11441/92552 [10 febrero 2020].

Martín Vera, Manuel Ángel, "Tácticas terrestres en la Castilla bajomedieval, siglos XIV-XV". Aequitas, 16 (2020), pp. 111-143. 
Memorias de Don Enrique IV de Castilla, Colección diplomática, ed. RAE, Fortanet, Madrid, 1835-1913, vol. 2.

Molina Molina, Ángel-Luis, (ed.), Documentos de Pedro I. Colección de Documentos para la Historia del Reino de Murcia [CODOM], Real Academia Alfonso X el Sabio, Murcia, 1978, vol. 7.

Nogales Rincón, David, "La monta a la gineta y sus proyecciones caballerescas: de la frontera de los moros a la corte real de Castilla (siglos XIV-XV)", Intus-Legere Historia, (13-1), 2019, pp. 37-84.

Palacios Martín, Bonifacio, (dir.), Colección diplomática medieval de la Orden de Alcántara (1157?-1494). De los orígenes a 1454, Complutense, Madrid, 2000, vol. 1.

Palacios Ontalva, José Santiago, "Una aproximación al concepto de «lanza» en relación a las Órdenes Militares", Entre Deus e o Rei. O Mundo das Ordens Militares, Isabel Cristina Ferreira Fernandes (coord.), Municipio de Palmela-GESOS, Palmela [Portugal], 2018, vol. 1, pp. 297-320.

Pardo de Guevara y VAldÉs, Eduardo, “La revolución hermandiña de 1467”, Revista de Historia Militar, 44 (1987), pp. 7-39.

Pascual Martínez, Lope, (ed.), Documentos de Enrique I, CODOM, Real Academia Alfonso X el Sabio, Murcia, 1983, vol. 8.

Pérez de Guzmán, Fernán, "Crónica del rey Don Juan Segundo”, ed. Cayetano Rosell, Crónicas de los reyes de Castilla, BAE 68, Atlas, Madrid, 1953, vol. 2.

Polite Cavero, Carlos Miguel, Guía de indumentaria medieval masculina, 2010, [S.1., s.n.].

Pulgar, Hernando del, “Crónica de los Reyes Católicos”, ed. Cayetano Rosell, Crónicas de los reyes de Castilla, BAE 70, Atlas, Madrid, 1953, vol. 3.

QuATREFAges, René, La revolución militar moderna: el crisol español, Ministerio de Defensa, Madrid, 1996.

Real Academia de la Historia [RAH], (ed.), Córtes de los antiguos reinos de León y de Castilla, RAH., Impr. M. Rivadeneyra, Madrid, 1863, vol. 2.

SAIz, Jorge, "Una clientela militar entre la Corona de Aragón y Castilla a fines del siglo XIV: caballeros de casa y vasallos de Alfons d'Aragó, conde de Denia y marqués de Villena”, En la España Medieval, 29 (2006), pp. 97-134.

Sánchez Saus, Rafael, "Sevilla y la frontera (1446-1452): una economía de guerra", Cuadernos de la Biblioteca española de Tetuán, (23-24) 1981, pp. 133-148.

SÁNCHEZ SAUS, Rafael, "La frontera en la caracterización de la aristocracia andaluza. El memorial de servicio de los Orbaneja de Jerez (1488)", Historia, Instituciones, Documentos, 13 (1986), pp. 283-314.

Soler del CAMPo, Álvaro, La evolución del armamento medieval del reino CastellanoLeonés y Al-Andalus (siglos XII-XIV), Universidad Complutense, Madrid, 1991 [Tesis doctoral]. 
Soler del CAMPo, Álvaro, El armamento medieval hispano, Cuadernos de Investigación Medieval, 6 (1986), vol. 3, pp. 523-524 [Otro: Ed. A-Z, Madrid, 1986].

Sotтo y Montes, Joaquín, "Organización militar de los Reyes Católicos (1474-1517)”, Revista de Historia Militar, 14 (1963), pp. 7-47.

Soтто, Serafín María de, Conde de Clonard, Historia orgánica de las armas de infantería y caballería españolas desde la creación del ejército permanente hasta el día, Impr. B. González, Madrid, 1851, vol. 2.

VAlera, Mosén Diego de, "Memorial de diversas hazañas", ed. Cayetano Rosell, Crónicas de los reyes de Castilla, BAE 70, Atlas, Madrid, 1953, vol. 3.

Villani, Filippo, Croniche di Giovanni, Matteo e Filippo Villani, Trieste, 1858, vol. 2. Zurita, Jerónimo, Los cinco libros postreros de la primera parte de los Anales de la Corona de Aragón, Iuan de Lanaja y Quartanet, Zaragoza, 1610, vol. 1.

\section{Diccionarios, vocabularios y léxicos militares históricos}

Almirante Torroella, José, Diccionario militar, Ministerio de Defensa. Secretaría General Técnica, Madrid, 2002, 2 vols.

D'Wartelet, Jorge, Diccionario Militar, Imp. de D. Luis Palacios, Madrid, 1863.

GaGo-Jover, Francisco, Vocabulario militar castellano (siglos XIII-XV). Universidad de Granada, Granada, 2002.

Gago-Jover, Francisco, "El léxico militar en el Poema de Alfonso XI". Cuadernos del Instituto de Historia de la Lengua, 7 (2012), pp. 457-509.

\section{Diccionarios académicos}

Nuevo tesoro lexicográfico de la lengua española (NTLLE). Para todos: http://buscon. rae.es/ntlle/SrvltGUILoginNtlle [fechas consulta entre corchetes]:

Alemany y Bolufer, José, Diccionario de la lengua española, Ramón Sopena, Barcelona, 1917 [16 marzo 2020].

Covarrubias, Sebastián de, Tesoro de la lengua castellana o española, Impr. Luís Sánchez, Madrid, 1611 [14 marzo 2020].

Real Academia Española [RAE], Diccionario de la lengua castellana, Madrid: Impr. Francisco del Hierro, 1726, vol. 1 [15 marzo 2020].

Real Academia Española [RAE], Diccionario de la lengua castellana, Impr. Francisco del Hierro, Madrid, 1729, vol. 2 [22 marzo 2020].

Real Academia Española [RAE], Diccionario de la lengua castellana. Madrid: Viuda de Francisco del Hierro, 1732, vol. 3 [17 abril 2020]. 
Real Academia Española [RAE], Diccionario de la lengua castellana, Impr. de I., Madrid, 1737, vol. 5 [05 abril 2020].

Real Academia Española [RAE], Diccionario de la lengua castellana, Joachín Ibarra, Madrid, 1780 [25 abril 2020].

Real Academia Española [RAE], Diccionario de la lengua castellana, Viuda de Joaquín Ibarra, Madrid, 1791, $3^{\mathrm{a}}$ ed. [20 febrero 2020].

Real Academia Española [RAE], Diccionario de la lengua castellana, Viuda de Ibarra, Madrid, 1803, $4^{\circ}$ ed. [22 marzo 2020].

Real Academia Española [RAE], Diccionario de la lengua española [en línea], RAE, [S.1.], 2014, 23 $3^{\mathrm{a}}$ ed., https://dle.rae.es/ [05 febrero-02 junio 2020]. 